\title{
11 \\ Unconditional Forgiveness and Normative Condescension
}

\author{
David Beglin
}

\subsection{Introduction}

In a typical case of forgiveness, we forgive someone because they (come to) appreciate that what they did was wrong. They might express their appreciation of this fact through apology or through attempts to make amends, or we might learn about it in some other way, perhaps through observation or through a mutual friend. In any case, forgiveness is typically conditioned upon the other person's attitudes towards what happened. Not all forgiveness, though, has this character. We sometimes forgive despite the fact that the other person refuses to apologize, despite the fact that the other person feels no remorse or regret or guilt about what they did. Such forgiveness isn't conditioned upon anything about the other person's attitudes towards what happened. It is 'unconditional' forgiveness.

Theorists disagree about the moral value of unconditional forgiveness. Some take it to be good, laudable, perhaps especially so. ${ }^{1}$ Others argue that unconditional forgiveness is morally problematic. Those who argue against unconditional forgiveness have typically worried that the unconditional forgiver fails to relate appropriately to what happened. Some, for instance, have argued that such forgiveness isn't self-respecting, because it fails to take seriously one's own right to be treated appropriately. ${ }^{2}$ Others have argued that unconditional forgiveness fails to take seriously wrongdoing and thus risks condoning it. ${ }^{3}$

1 See, e.g., Holmgren 1993, 2012; Garrard and McNaughton 2003, 2011; Pettigrove 2004, 2012; and Gamlund 2010.

2 See Murphy 1982; Murphy and Hampton 1988; Novitz 1998; and Griswold 2007.

3 See Kolnai 1973; Swinburne 1989; and Griswold 2007. 
In this chapter, I argue that the moral value of unconditional forgiveness is more complicated and constrained than many have taken it to be. This isn't, though, because I think the unconditional forgiver fails to relate appropriately to what happened. Rather, my worry has to do with how the unconditional forgiver relates to the person being forgiven. When we unconditionally forgive, I argue, we attempt to settle a matter of interpersonal significance without regard for the other person's perspective on that matter. Other things being equal, this is a problematic way to relate to people. It is, I suggest, normatively condescending, failing to take them seriously as a participant in our relations with them and thus belittling the place of their agency within those relations.

This doesn't mean, though, that unconditional forgiveness is wholly bad or impermissible. Unconditional forgiveness, I argue, can also serve certain valuable social and moral functions. But even when it does, there is something lamentable about it. An important way of relating to others is given up.

\subsection{Some initial cases}

The literature on forgiveness typically focuses on the victim of a clear wrongdoing, asking questions about the reasons such a victim has to forgive, about whether the victim can owe it to the wrongdoer to forgive, and generally investigating the moral psychology of forgiveness in this context. This focus on an obvious victim, I suspect, helps to explain why discussions of unconditional forgiveness have tended to be preoccupied with how the forgiver relates to what happened. I'd like to begin, then, with an eye towards something else. Before considering unconditional forgiveness more broadly, I'd like to start by considering a number of cases from the perspective of the person being forgiven. These are cases in which the person being forgiven seems reasonably put off or insulted by the unconditional forgiveness that they receive. These cases, I believe, draw attention to a general feature of unconditional forgiveness, a feature that is relevant for assessing its moral value but that has been overlooked by extant discussions of it.

Let's start with a case of what we might call 'false forgiveness', a case in which the person being forgiven rightly feels that they haven't done anything wrong. Consider, for example, the following:

Kim. Kim comes out to her parents as bisexual. Her parents don't take this well. They respond with anger and disgust. They raised her better, they 
insist; this is a violation of morality and a betrayal of them. Ultimately, they kick Kim out of the house. Months later, though, Kim's parents contact her. They explain that they want to reconcile-they forgive her.

It seems reasonable for Kim to feel insulted by her parents' 'forgiveness' in this case. Why is this, though? What makes it so offensive?

One possible explanation comes from Glen Pettigrove. Forgiveness, Pettigrove observes, expresses the rejection on moral grounds of the wrongdoer's moral failing.' It implies, in other words, that one is 'in need of forgiving.' And this, Pettigrove continues, provides an explanation for why false forgiveness, like that of Kim's parents, is offensive: 'We take offense because forgiveness expresses the importance of certain standards alongside the forgiver's belief that we have fallen short of them' (Pettigrove 2012, 120). Pettigrove doesn't elaborate on this, but I take his idea to be that false forgiveness can be offensive because it contradicts either our own sense of what standards are important or our own assessment of how our behavior measures up to those standards. And in this respect, Kim seems justified in feeling offended. Her parents' forgiveness certainly reflects wrongheaded views of morality.

Pettigrove's suggestion seems to capture an aspect of why it is offensive to be forgiven when we don't feel we've done anything wrong. Still, I think there is more to it. Consider, for instance, how Kim's parents reacted in the first place. They reacted with anger and disgust; they blamed her. This blaming response, like their forgiveness, implies that Kim is falling short of a wrongheaded moral standard-the very same standard their forgiveness invokes. But the parents' forgiveness seems offensive in a way that goes beyond their initial blame. Their forgiveness seems distinctively insulting; it is somehow more audacious than their blame. And Pettigrove's suggestion doesn't quite seem to capture this.

We need to say more, then, about Kim's case. Her parents' forgiveness is no doubt problematic because it reflects wrongheaded moral views; however, it also seems to reflect something else, a kind of failure to engage with Kim appropriately. We can observe something similar in other cases of unconditional forgiveness, even cases in which the person being forgiven agrees that they've done something wrong.

Consider, for example, another case:

Odette. Odette cancels her dinner plans with Akeem, and Akeem becomes upset. This is the third time Odette has canceled their plans. 
Odette responds impatiently, asking him to be more understanding. 'You know I'm worried about getting passed up for a promotion', she complains. Akeem won't hear it. He tells her that this doesn't excuse her from showing up to their friendship. Odette counters, insisting that he should be there for her. The conversation ends without resolution. A few days pass, and Odette starts to think Akeem was right; she's been neglectful. Before she gets a chance to express this or to apologize, though, Akeem calls her and leaves a message: he wants to put what happened behind them; he forgives her.

Here, Odette, like Kim, might reasonably be put off or insulted by the forgiveness she receives. Akeem's forgiveness, much like that of Kim's parents, seems audacious, presumptuous. Crucially, though, Odette agrees with Akeem that she was in the wrong, that she did something that might ultimately call for forgiveness. Still, in forgiving her like this, without regard for her perspective or their previous disagreement, before she's gotten a chance to acknowledge that she was wrong or to play a role in initiating forgiveness, Akeem seems to be engaging with Odette in a problematic way.

Something similar seems to be going on in a final case:

Ben. Ben betrayed his close friend Julia's confidence. Without thinking, he revealed something embarrassing that he shouldn't have to their friendgroup. He feels terrible about it; it has had disastrous effects. Ben tells Julia what he did, and insists that he doesn't want her forgiveness until he can make amends. It's important to him that he earns her forgiveness. Julia tells Ben that it doesn't matter-she forgives him anyways.

My sense is that Ben might reasonably be put off by Julia's forgiveness here. It seems like Ben's hope to earn her forgiveness should carry more weight. But even if it shouldn't, we can make the case stronger if we imagine that Julia's comment- it doesn't matter'-means that she would have forgiven Ben even if he hadn't apologized or felt remorse, if she means to say that her forgiveness is truly unconditional. In this case, it is easy to imagine Ben feeling displaced, somehow insulted, by his friend's apparent disinterest in his apology and remorse, in his desire to make amends. It might reasonably seem important to him that his attitudes have a role in bringing about her forgiveness.

Kim, Odette, and Ben, then, all strike me as being reasonably put off by the forgiveness that they receive. Crucially, though, this doesn't seem to be because, or at least (in Kim's case) only because, they aren't in need 
of forgiveness. Rather, what's offensive seems like it has to do with how the forgiver treats them. ${ }^{4}$

\subsection{A morally significant feature of unconditional forgiveness}

What's gone wrong with the forgiveness in the foregoing cases? The problem, I believe, lies in the way that the forgivers attempt to settle a matter of interpersonal significance without regard for the other person's perspective on that matter. And if this is right, it raises a moral question about unconditional forgiveness more generally.

To start, it will help to get clearer about what is involved in forgiveness. When we forgive someone, we purport to change our relations with that person, to resolve a moral conflict, to establish a new baseline for our interactions with them. Crucially, however, to offer forgiveness is to attempt to accomplish this in a particular way. Compare forgiveness, for example, to merely letting go or moving on from something. Imagine that Akeem, instead of offering forgiveness, called Odette and said, 'Look, it hurt my feelings when you canceled our plans, but I understand you have a lot going on right now. Why don't we just forget about it?' Here, Akeem, in suggesting that he and Odette just forget it, is attempting to resolve their conflict. Crucially, however, suggesting that they move on like this doesn't seem presumptuous like his forgiveness in the original case. And this, I propose, is because forgiveness and merely moving on are importantly different ways of attempting to resolve the issue. ${ }^{5}$

When we move on from something, when we just let it go, we needn't have any settled understanding of it. More importantly, we needn't take it to

\footnotetext{
${ }^{4}$ One might argue that these cases are offensive simply because of the way the forgiver expresses their forgiveness. For example, one might think that Kim's parents are audacious for telling Kim that they forgive her. If this is all that is going on, there might be nothing wrong about their forgiveness itself. I doubt this is right, though. One could imagine Kim learning that her parents forgave her in some other way, perhaps from a friend who overheard them talking about it. And one could imagine Kim being just as offended.

${ }^{5}$ One might object. It might seem like the key difference is just that in our new case Akeem invites an exchange. Perhaps what's problematic about the forgiveness in the original case, then, is that Akeem simply forgives Odette, without inviting an exchange. I doubt this is right. First, in a moment I'll consider a case of unilateral moving on that doesn't seem like it is problematic. But second, we could reimagine our original case. Akeem, instead of just forgiving Odette, might say that he's ready to forgive her and ask her to call him back. Here, Akeem invites an exchange, but he is still being audacious. And this audacity, I'll argue, is tied up with the practical significance of offering forgiveness. Thanks to a reviewer for help here.
} 


\section{DAVID BEGLIN}

have any settled public meaning. Imagine, for example, that your friend makes a joke that leaves you feeling hurt. Let's say, though, that you have doubts about whether this reaction is appropriate. Perhaps you worry that you're being too sensitive, or maybe you're unsure if the joke meant what you initially thought. In light of these doubts, you might simply decide to let it go, to shake it off and move on. By contrast, forgiveness in this situation seems out of place. Your uncertainty about how to understand what happened cuts against the idea that forgiveness is an option. One can't forgive and leave open the meaning of what happened like this. ${ }^{6}$

Here, then, is one notable difference between forgiving and merely moving on. Akeem, in suggesting that he and Odette move on, doesn't presuppose that Odette did anything transgressive or inappropriate. He leaves open the meaning of her canceling their plans. Of course, this doesn't mean that he doesn't believe it was wrong of her to do this. The point, rather, is that in attempting to just move on, Akeem aims at a resolution to their conflict that doesn't build in any particular understanding of Odette's behavior. In this respect, Akeem provides space for an alternative perspective on what happened. His forgiveness in the original case, by contrast, isn't like this.

That forgiveness can't leave open the meaning of what happened is tied up with the larger practical significance of forgiving and being forgiven. Forgiveness only makes sense in a particular context. When we forgive someone, we purport to change the bearing that what they did-their transgression, their wrongdoing-has on our relations with them. We might communicate, for instance, that they can now expect our interactions with them to be more cordial, less distant and cold, or no longer infused with hard feelings (Calhoun 1992, 77). Or we might, as Pamela Hieronymi puts it, agree 'to incorporate the injury into [our] own life without further protest and without demand for retribution' (Hieronymi 2001, 551). However we articulate the idea, the presupposition is that the person being forgiven isn't entitled to what the forgiver offers. They aren't already entitled to the cordiality that our forgiveness promises; they aren't already entitled to our incorporating the injury into our life without protest. Forgiveness thus purports to do something for the person being forgiven. ${ }^{7}$ This, no doubt, is why theorists often emphasize that forgiveness is 'elective', something 'given, a

\footnotetext{
${ }^{6}$ For similar observations, see Hieronymi 2001, 530-1 and Pettigrove 2012, 4-5. Cf. also Gary Watson's (2013) discussion of acceptance.

7 The idea here is related to, though importantly different from, another prominent idea regarding forgiveness: that to forgive is to exercise a 'normative power,' changing the landscape of obligations and duties (see Owens 2012; Warmke 2016; and Bennett 2018).
} 
kind of 'gift.' It is also why we often associate forgiveness with virtues like generosity and magnanimity.

Forgiveness, then, unlike merely moving on, presumes that the other person did something transgressive, something with social, emotional, and relational costs, which the forgiveness addresses. Forgiveness presumes to change the bearing that the other person's transgression has on our relations with them. This helps to bring out what is problematic when forgiveness is unconditional.

In a typical case of forgiveness, our forgiveness comes after a process of apology or making amends, as a result of having addressed what happened with the other person. The other person's perspective about the meaning of what happened thus informs our forgiveness and the way we presume to resolve the matter. They assent to forgiveness, so to speak, along with the presumptions it makes about the meaning of what happened. ${ }^{9}$ Unconditional forgiveness, though, isn't like this. When we unconditionally forgive, we attempt to resolve a matter of interpersonal significance, a matter concerning the meanings and values at stake in our relations with the other person; however, we do so in a way that presumes a particular understanding of that matter, without regard for the other person's perspective on it. It's this aspect of unconditional forgiveness, I believe, that makes it problematic in our cases.

Consider Kim. When Kim's parents forgive her, their forgiveness is premised upon a particular understanding of things, namely, that Kim's sexual orientation and romantic choices are wrong, a betrayal, something appropriately responded to with anger and disgust. Of course, as Pettigrove's explanation brought out, this outlook is itself offensive. Still, there is also something distinctively audacious about the parents' forgiveness. This audacity, I think, is tied up with the way their forgiveness is completely unresponsive to Kim's perspective about the meanings and values at stake in their relations. That is, Kim sees things differently than her parents, and

\footnotetext{
8 There are surely cases in which we ought to forgive someone else. It isn't clear, though, that this means the person who ought to be forgiven is therefore entitled to forgiveness. Sometimes we deserve or merit something we aren't entitled to. Think here, e.g., of promotions. There is a similar phenomenon with gifts. Sometimes we can reasonably expect someone to give us a gift. Nevertheless, it seems that part of the idea of their giving a gift is that they elect to do so. In some sense, they are free not to give it.

9 Such 'assent' doesn't require literal exchange or permission. We sometimes conditionally forgive, for instance, after simply seeing that the other person feels terrible. Such conditional forgiveness is still responsive to the other person's perspective. And, as I'll argue below, this is what's crucial for understanding the difference between conditional and unconditional forgiveness.
} 
they know this. For Kim, there is nothing wrong about her sexual orientation or her romantic choices. Indeed, these things might be sources of pride for her, aspects of her identity that she sees as something to be celebrated, not disparaged. Still, her parents offer forgiveness anyways. And in doing so, they purport to resolve the moral conflict between them and their daughter, but in a way that precludes the possibility of disagreement about what happened and, thus, that doesn't give Kim's perspective any standing. The parents, that is, interact with Kim as though the meaning of what happened is settled, despite Kim's disagreement. In this respect, they don't allow Kim's perspective to make any claim on them or their interaction with her. And this is, in an important sense, which I unpack in the next section, to exclude Kim from their relationship.

Something similar seems to be going on in Odette's case. Although Odette ultimately agrees with Akeem that she was in the wrong, Akeem doesn't know this. When he tells Odette that he forgives her, then, much like Kim's parents, he presumes to resolve their moral conflict, an issue of interpersonal significance, in a way that treats the meaning of that conflict as settled; and he does this without regard for Odette's perspective on the matter. Like with Kim's parents, this seems to be what makes Akeem's forgiveness offensive. His forgiveness is unresponsive to Odette's perspective.

Finally, the same feature seems to be central to understanding what has gone wrong in Ben's case. Ben, of course, has apologized to Julia. He's expressed contrition. Still, Ben doesn't think that this is enough. He wants to earn her forgiveness, to make up for what happened in some way. That Ben hopes for this is significant, because it reflects the meaning of what happened for him. Given the way he values their friendship, and given the way he relates to himself as a moral agent, what he did is unacceptable; it represents a significant moral failing. This speaks to an important point. Wrongdoings don't only carry meaning for the person wronged; they can also carry meaning for the person who commits them. Part of what's important about our ordinary practices of apology, making amends, and forgiveness, then, is the way that they allow us to address the meaning of what happened together. And this sheds some light on what is problematic about Julia's forgiveness. Her forgiveness isn't responsive to the meaning of what happened for Ben. We can magnify this if we imagine that Julia's forgiveness is truly unconditional, if it isn't conditioned at all on Ben's attitudes towards what happened. In this case, even if Ben agrees with the perspective inherent in Julia's forgiveness, it seems reasonable for Ben to feel displaced by her apparent disinterest in his agreement. If Julia's forgiveness is truly 
unconditional, this is to express that Ben needn't participate in the process of mediating the meaning of what happened. It is to imply the unimportance of his participation in their relationship, which is informed by how what happened is incorporated into it.

The problem with the unconditional forgiveness in our cases, then, seems rooted in the way that it attempts to resolve a matter of interpersonal significance, understood by the forgiver as having a particular settled meaning, without regard for the other person's perspective on that matter. This is, in some important sense, to exclude the other person from one's relations with them.

If this is right, it raises a question about unconditional forgiveness more broadly. After all, the feature that makes the forgiveness in our cases problematic, I've suggested, is a feature of all unconditional forgiveness. In light of this, how should we understand the moral value of such forgiveness? Is it always problematic? Should we disavow it? Or are things more complicated?

To answer these questions, we need a better sense of what's at stake in unconditional forgiveness. Let's begin, in the next section, by considering in more detail the way in which unconditional forgiveness is exclusive. We'll then, in later sections, be able to speak to why it is important that we not be exclusive like this and what constraints this might put on the value of unconditional forgiveness.

\subsection{Taking each other seriously as participants in moral life}

In our cases, Kim, Odette, and Ben all take exception to the way the forgiveness that they receive excludes them from their relations with the other person. There thus seems to be some sense in which unconditional forgiveness doesn't take the person being forgiven seriously as what we might call a 'moral peer, a fellow participant in the sorts of relations that characterize ordinary moral life. How should we understand this thought?

To treat someone as a moral peer, I propose, is to feel engaged in a particular way by their perspective concerning the meanings and values at stake in our relations with them; it is to treat them as a kind of interlocutor. This isn't to say, though, that we must ascribe credence to their perspective. Engaging with someone as a moral peer isn't primarily epistemic like this. Kim, for example, can take her parents seriously as fellow participants in her relations with them, while at the same time rejecting their moral views 
about human sexuality and filial obligation. The idea, rather, is that to treat someone as a moral peer is to take what's at stake in our relations with them to be socially mediated; it is to take our relations with that person to involve a kind of negotiation of meaning and value. Agreement and disagreement about what should matter thus take on special significance. If the other person sees things differently, this marks a problem, a breakdown that challenges our own perspective about the meanings and values at stake in our relations with them. And resolving this problem means arriving at a shared understanding of what should matter, a shared way of going on together. ${ }^{10}$

To be clear, I'm not saying that to relate to someone as a moral peer is to see oneself as constructing the 'moral truth' with them. I might believe that certain things should matter, and I might believe that this is true, regardless of what you think; but how you see things might still be important to me. And this isn't only for instrumental reasons. To relate to you as a moral peer, I'm suggesting, is to see us as mediating the meanings and values at stake between us. I might thus feel strongly that something should matter within our relationship. But if you see things differently, this marks a problem. Our disagreement represents a breakdown in our actual relations; it calls into question how certain values figure into them and thus challenges my perspective concerning what's at stake between us. ${ }^{11}$

Return to Kim. Kim might feel hurt or resentful or indignant about her parents' moral views. These kinds of responses, I think, are indicative of the significance that she ascribes to her parents' perspective, to the way agreement with them on the meaning of her sexual orientation and romantic choices matters to her. The fact that her parents see things differently than she does leaves Kim feeling unsatisfied and alienated, perhaps personally challenged. Reacting to her parents like this, though, doesn't mean that Kim must have doubts about the correctness of her own moral outlook. Rather, such responses simply reflect the way she's invested in their perspectives. How they see things can challenge or affirm her. In this case, their perspective suggests a certain picture of what should matter that Kim finds

\footnotetext{
${ }^{10}$ I gesture at the ideas here in Beglin 2020, and I develop them more fully in my manuscript, 'The Participant Attitude and the Moral Psychology of Responsibility'.

11 If there is moral truth independent of our relations, aren't the meanings and values at stake in them just determined by that truth? We can certainly talk about objective meaning. But I doubt this exhausts what's at stake within the context of ordinary human relationships and communities. It's cold comfort for Kim, for example, to know that her sexual orientation isn't wrong. If her parents see things differently, it doesn't change the objective meaning of her sexual orientation; but it nevertheless bears on her relationship with them and how certain values are taken up within it. And this itself might matter to Kim.
} 
unacceptable. This is a problem. It represents a breakdown that challenges her own conception of the meanings and values at stake in her relations with them. And such a breakdown might lead to a variety of reactions. It might leave Kim feeling alienated and hurt, or it might leave her feeling defiant; it might lead her to resent her parents from afar or to confront them.

I doubt that relating to someone as a moral peer, in the sense I've just articulated, is a particularly exceptional or demanding way to relate to someone. In fact, it is reflected throughout the responsibility practices that undergird our ordinary moral relations. Indeed, as many theorists have pointed out, those practices typically have a dialogical character. ${ }^{12}$ In paradigmatic cases of blame or moral criticism, we communicate our expectations to the other person, our conception of what should matter within the context of our relations with them. And when we do, we presume their capacity to engage with our message appropriately. That is, we expect them to take up our response to them, our resentment or indignation, our disapproval. We expect them to explain or to justify themselves, or maybe simply to recognize the import of what they did, to acknowledge their fault and to apologize. More to the point, it is important to us that they respond in these ways. If they don't, it is unsatisfying; it leaves things unsettled. We might even resent someone for being unresponsive in this context. Such behaviors and reactions reflect our relating to that person as a moral peer, whose perspective bears on the meanings and values at stake between us. This, I believe, is why we're prone to react in the ways we do, why disagreement can be painful, why getting a response can feel so important. ${ }^{13}$

On the other hand, when we're blamed, we typically feel called on to respond. And again, this reflects our engaging with the person blaming us as a fellow participant with us in moral life. We might feel bad upon being blamed; we might come to see that we were wrong and to apologize. Or we might feel, with some urgency, the need to explain or justify our behavior. These are ways of recognizing our own role in the negotiation of meaning and value. Alternatively, we might ourselves become resentful or indignant, perhaps because the person's blame reflects a moral outlook that contradicts

\footnotetext{
12 See, e.g., Watson 1987; Walker 2006; Shoemaker 2007, 2015; McKenna 2012; Smith 2013; Macnamara 2015; and Fricker 2016. I draw especially on McGeer 2012.

13 This isn't to say that all blame reflects this way of relating to people. Sometimes our interest in blaming other people outstrips our interest in what's actually at stake in their action, given their perspective and reasons for acting. This is sometimes the case when we hate another person. We might presume that whatever they do is wrong, and we might blame them without interest in a response. When blame takes this form, I think it is worrisome like unconditional forgiveness, though also less redeemable.
} 
our own. To resent or to feel indignant in this context, however, isn't to ignore the other person's criticism; it is, rather, to feel challenged by it, to protest it. ${ }^{14}$ The conversation continues.

The idea here, then, is that to take someone seriously as a fellow participant in the kinds of relations that characterize ordinary moral life is to ascribe a kind of interpersonal significance to their view of what matters. It is to allow their normative perspective to bear on the meanings and values at stake between us, and so to be capable of challenging or affirming our own conception of these things. We thus take their perspective to bear on the very nature of our relations with them. When we disagree with this person, it matters; it marks a breakdown that challenges our conception of what should matter between us. And resolution in this context means finding a common ground, a shared understanding of what meanings and values are at stake in our relations with them. ${ }^{15,16}$

This helps to shed light on the sense in which unconditional forgiveness is exclusive. Unconditional forgiveness attempts to resolve a matter of interpersonal significance, understood by the forgiver as having a particular settled meaning; but it does so in a way that ignores the perspective of the person being forgiven. In this respect, it doesn't appear to take the person being forgiven seriously as a moral peer.

Again, it is helpful to contrast unconditional forgiveness with other ways we might go about attempting to resolve a moral conflict. Earlier, for example, we imagined Akeem suggesting to Odette that they 'just forget about it.' This way of attempting to resolve their moral conflict, I suggested, didn't seem problematic in the same way as Akeem's unconditional forgiveness in the original case. We're now in a position to say more about this.

To suggest that they move on in this context is to suggest that they agree to disagree. And this is consistent with taking Odette seriously as a participant in their relations. ${ }^{17}$ It is a distinctive way of attempting to resolve their disagreement; it seeks a second-order shared understanding of how to go

14 See, e.g., Hieronymi 2001; Talbert 2012; and especially Smith 2013.

15 Of course, we don't always find resolution. We often simply have to make do with disagreement. Crucially, though, this doesn't mean that such disagreement doesn't matter. It often continues to manifest itself in perennial disputes or quarrels; it often remains unsettling.

${ }^{16}$ I don't mean to argue that we ought to always relate to people like this. But as I'll argue in the next section, I think we have good reason to.

${ }_{17}$ This isn't to say that in attempting to move on from something we cannot possibly fail to take someone seriously as a moral peer. The point is simply that moving on can be consistent with this way of relating to someone. Unconditional forgiveness, I'm suggesting, can't be. 
on together. In this respect, it is responsive to Odette's normative perspective; it engages with her in a way that allows her perspective to bear on their relations. Akeem's unconditional forgiveness, though, cannot be responsive to Odette's normative perspective like this. And this is because Akeem's unconditional forgiveness attempts to resolve their conflict, a matter tied up with the meanings and values at stake in their relations, but only understood in a particular way and without regard for Odette's perspective on that issue. This reflects a disengagement from Odette's perspective that is in tension with relating to her as a moral peer.

I'm suggesting, then, that unconditional forgiveness is exclusive in the sense that it doesn't treat the person being forgiven like a moral peer. In this respect, the unconditional forgiver isn't responsive to the normative perspective of the person whom they forgive; the forgiver engages with that person in a way that suggests a disinterest in that person's view of what should matter, in a way that doesn't allow that person's perspective to bear on the forgiver's relations with them. But what is morally significant about engaging with people as moral peers? Why is it important? And what implications does this have for how we should think about the moral value of unconditional forgiveness?

\subsection{Normative condescension and the importance of taking each other seriously}

The importance of taking each other seriously as moral peers, I believe, is tied up with the importance of relating to each other as moral agents. That is, as moral agents we are capable of forming meaningful evaluations and judgments, conceptions of what things mean and what should matter that are tied up with our senses of self and how we understand our place in the world. Such evaluations and judgments constitute our normative perspective. In this respect, if I don't allow your normative perspective to bear on my relations with you, then I don't allow your moral agency to bear on those relations. If I don't take you seriously as a moral peer, in the sense articulated above, I don't take you seriously as a moral agent.

What I'm proposing, then, is that unconditional forgiveness is worrisome because it, at bottom, doesn't take the person being forgiven seriously as a moral agent. Interestingly, some theorists have suggested the opposite. It is sometimes suggested that unconditional forgiveness is laudable precisely as 
a way of respecting people as moral agents. This line of thought has been defended most prominently by Margaret Holmgren. ${ }^{18}$ It will thus be useful to contrast Holmgren's proposal with my own.

According to Holmgren, moral agency 'is simply the capacity for moral choice, growth, deliberation, and awareness' (Holmgren 2012, 90). And to respect such agency, she holds, we must 'recognize the inherent worth of an individual possessing these basic moral capacities.' This means having a 'positive response' to that individual, rather than responding to them negatively or with hostility. It also means desiring for that person to 'grow and flourish' (Holmgren 2012, 90).

This characterization of what goes into respecting someone as a moral agent plays an important role in Holmgren's arguments. Holmgren aims to defend the superiority of forgiveness over retributive attitudes. Part of her point, then, is that forgiveness is consistent with what it is to respect someone as a moral agent. It involves responding to them positively, without hostility, despite their wrongdoing, and it avoids reducing the person to their wrongdoing, thus taking seriously their capacity to mature and grow. On the other hand, retributive responses, according to Holmgren, run afoul of these aspects of respecting moral agency. While retributive attitudes might 'track' people's moral agency, Holmgren argues, they don't respect people as moral agents in the robust sense that she has in mind; they fail to engage with the person as a 'developing, experiencing, vulnerable human being' (Holmgren 2012, 92).

So far as it goes, I'm sympathetic with Holmgren's general worries about strong retributive responses. I suspect that the world would be a better place if we were generally softer, gentler, and more forgiving. Still, I think that Holmgren overstates things. In particular, I doubt that the choice is really between retribution and forgiveness. There is plenty of room for attitudes in between. After all, we can surely blame people, perhaps even resent them, without having strong retributive feelings. Moreover, even if blame and resentment necessarily involve retributive feelings, we can move on from wrongdoing, ceasing to blame and resent, without forgiving. I thus doubt that forgiveness is required to get past retribution.

More to the point, however, and setting these latter reservations aside, I worry that Holmgren operates with an impoverished idea of what it is to interact with and respect someone as a moral agent. In particular,

18 See Holmgren 1993; 2012, ch. 3. For a critical discussion of Holmgren's view that is sympathetic with unconditional forgiveness, see Garrard and McNaughton 2003. 
her conception of respecting people as moral agents strikes me as too individualistic, overlooking the role that moral agency plays in shaping and undergirding our social lives. The value of moral agency, it seems, is deeply connected to our participation with each other in rich moral relations, which are essentially mediated through exchanges that implicate our moral agency.

Take Kim. We can stipulate that by the time her parents forgive her, they've adopted a positive stance toward her, forgoing their initial hostility. Moreover, we can stipulate that they're genuinely invested in Kim's moral growth and flourishing. Their forgiveness, we can say, reflects a genuine concern for her as a 'developing, experiencing, vulnerable human being.' Finally, it doesn't seem that Kim's parents, in forgiving her, are interfering with Kim's standing to make her own choices or author her own development, a further aspect of respecting moral agency that Holmgren notes (Holmgren 2012, 93). Even granting all of this, though, it seems that Kim might reasonably complain about how her parents relate to her as a fellow moral agent. What more might Kim want?

My sense is that Kim might reasonably want her moral agency to have more of a bearing on her relations with her parents. Within the context of ordinary moral relations, that is, we don't simply want people to respond to us positively, to be concerned about our growth and development, and to avoid interfering with our deliberation and choices. We also want people to feel the force of our viewpoint; we want our normative perspectives to be taken up, to have efficacy. If our normative perspectives are ignored, if they aren't allowed such efficacy, then this, as I've suggested, is importantly to exclude us from the relevant relationship.

Moral agency, then, isn't simply about being able to believe the right things or to perform the right actions. Nor is it simply about being able to choose and act freely, without constraint. Moral agency is also tied up with our participation in ordinary relationships, which are mediated through interaction, normative exchanges that bear on what's at stake between us and other people. To eschew such interaction and exchange with someone is to circumscribe that person's moral agency; it is to diminish the place of that person's moral agency within the context of our relationship with them. And this is to adopt an attitude of superiority with respect to them, implicitly taking it that one's own moral agency should play a greater role than theirs in shaping one's relations with them.

I think that this helps to bring out what is worrisome about unconditional forgiveness. It is, I believe, normatively condescending. It involves, in 
other words, engaging with someone as their normative superior, as though one's own normative perspective, one's own moral agency, carries more legitimacy, has more bearing, within the context of one's relations with them.

It is instructive to compare unconditional forgiveness to other ways we might normatively condescend to someone. Consider, for instance, conservative groups who pray for women who have abortions, without regard for their views about their choice. To quote a prayer guide, distributed by the Archdiocese of Miami, these groups 'pray for all those involved in past abortions that they will be able to be healed from this terrible atrocity' ('Abortion Clinic Prayer,' n.d.). Like unconditional forgiveness, such prayers are unresponsive to the other person's perspective. Consider the language of the quoted prayer. It presumes that the decision to have an abortion can only have one meaning and that those who make this decision are thus in some way morally damaged. But it isn't just having this view that is the issue. It is this combined with the fact that the prayer purports to do something for the other person. It calls for God to intervene, to inspire a change of heart. Notably, this is to forego actually engaging with the person being prayed for. It is to eschew communication and interaction, to limit the place of their perspective in the relevant relations. This reflects contempt for the other person's moral agency. Like unconditional forgiveness, it is condescending.

Paternalism, too, seems normatively condescending like this. Imagine, for example, that Carla learns about a professional opportunity that her partner, Alex, will surely be interested in. Carla thinks that it would be a bad idea for Alex to pursue this opportunity. Perhaps she thinks it would be immoral or a waste of time. Or maybe she thinks it would require a reorientation in priorities that would mean Alex, by Carla's lights, would live a less meaningful life. Let's say that, with these worries in mind, Carla makes it a point to keep Alex from hearing about the opportunity. Here, Carla is behaving paternalistically. What is problematic about this? Carla interferes with Alex's standing to make his own decisions, of course; but part of the insult, as Seana Shiffrin convincingly argues, rests in how Carla relates to Alex as a moral agent. She engages with him as though her own normative perspective, her own moral agency, is superior (Shiffrin 2000, 211-20). And this is condescending in much the same way as unconditional forgiveness and unilateral prayer. Carla isn't responding appropriately to Alex as a fellow moral agent; she doesn't allow Alex's perspective to bear on her relations with him. She doesn't engage with Alex as someone with whom she shares in those relations. 
Drawing the connection between what's worrisome about paternalism and what's worrisome about unconditional forgiveness is especially helpful. It offers two lessons for thinking about normative condescension and, thus, the ethics of unconditional forgiveness.

First, it is widely recognized that paternalism is problematic even if the paternalist is right to think that her judgment is better than the person towards whom she is paternalistic. This speaks to the logic of condescension more generally. We can condescend to someone even if they are, in fact, less capable than us in the relevant domain. If you don't take my question seriously during a conference presentation, for instance, because you correctly judge that I'm an inferior scholar, I can still complain that you are being condescending. And this is because in this context your superiority doesn't entitle you to engage with me as your inferior. We can say something similar about our moral relations. It seems reasonable that we insist on having our normative perspectives, our moral agency, bear equally on our relations with one another, even if there are differences in our actual abilities as moral agents. ${ }^{19,20}$

Second, paternalism represents another situation in which our agreement with someone's perspective or with the outcome of their behavior doesn't mean that we haven't been insulted. That is, even if Alex would ultimately agree with Carla that he shouldn't pursue the professional opportunity that she is paternalistically hiding from him, even if he already heard about it and declined to pursue it, he might still be offended if he finds out about how Carla behaved towards him. And this is because of the way Carla is oriented toward his agency in acting paternalistically (Shiffrin 2000, 214-15). Likewise, as we saw above, Odette and Ben might still be reasonably put off by the unconditional forgiveness that they receive, despite agreeing that they've done something wrong, even despite ultimately wanting forgiveness. Like paternalism, the problem with unconditional forgiveness lies in the way that the unconditional forgiver is oriented toward the person whom they forgive.

\footnotetext{
19 Again, the point here isn't epistemic. Just as it isn't condescending to completely reject my particular philosophical ideas, it isn't condescending to completely reject my moral views. It might be condescending, however, to reject my views in either domain without any critical engagement with them.

${ }_{20}$ There are limits here. If I'm an infant or have certain severe forms of mental illness, my capacity as a moral agent might be so diminished or impaired that I'm not entitled to treatment as a moral peer. It's worth noting, though, that this caveat shouldn't be relevant in the context of unconditional forgiveness. Forgiveness implies that the person being forgiven is capable enough to be engaged with as a responsible agent, and in this sense meets whatever threshold there is for status as a moral peer.
} 
Let's take stock. In this section, I set out to consider why it is important that we take each other seriously as moral peers, and I argued that it is tied up with the importance of taking each other seriously as moral agents. That is, the value of our moral agency derives, in part, from the role that it plays in undergirding and shaping our relations with each other. Indeed, ordinary moral relations are essentially mediated through normative exchanges, which implicate our moral agency. In this respect, when someone doesn't take us seriously as a moral peer, they condescend to us qua moral agents. They engage with us in a way that presumes that their normative perspective, their moral agency, should have more bearing within the context of our relations with them than our normative perspective, our moral agency.

Despite all I've said, I don't mean to argue that unconditional forgiveness is therefore always bad or impermissible. Just as we can sometimes permissibly, even laudably, behave paternalistically, I believe that there are cases in which unconditional forgiveness is good or laudable. Let's turn to this complication.

\subsection{The complicated moral value of unconditional forgiveness}

I've argued that unconditional forgiveness is worrisome because it doesn't take the person being forgiven seriously as a moral peer. This, I've suggested, diminishes the place of that person's moral agency within the context of our relations with them; it is normatively condescending. That unconditional forgiveness is condescending like this, I believe, gives us pro tanto reason against it. Other things being equal, that is, it is better if our relations are reciprocal, mediated through genuine normative exchanges. This does justice to our capacities as individual moral agents to form conceptions of what things mean and what should matter that are tied up with our senses of self and how we understand our place in the world.

Still, there are cases in which unconditional forgiveness seems good or laudable. Think here of the forgiveness that was operant in the civil rights movement, in America, or think of the way unconditional forgiveness functioned in the movements of Gandhi and Nelson Mandela. Or for a more singular, recent example, think of the way that family members of those slain in the Emanuel African Methodist Church shooting responded to Dylann Roof, the shooter. They publically forgave him. And they did so 
despite his continuing to espouse racist beliefs, despite his explicitly saying that he felt no remorse for his actions and the terror they caused. ${ }^{21}$

The unconditional forgiveness in such cases still presumes to settle a matter of interpersonal significance without regard for the other person's perspective. In this respect, it still diminishes the place of that person's moral agency within the context of the relevant relations. Insofar as that person is a moral agent, there is thus some reason against unconditional forgiveness. ${ }^{22}$ But still, the forgiveness in the foregoing cases strikes me as far from problematic. It seems good, admirable. What countervailing considerations might vindicate the forgiveness in these cases?

The most prominent defenses of unconditional forgiveness tend to emphasize its power as an expression of love or concern for the person being forgiven. As we saw above, this seems to run through Margaret Holmgren's proposal. A crucial part of respecting people as moral agents, for Holmgren, is being positively oriented toward their welfare qua moral agents. Likewise, Eve Garrard and David McNaughton argue that we have reason to unconditionally forgive as an act of human solidarity, out of a 'sense of shared moral weakness' (Garrard and McNaughton 2003, 57). Human nature, according to Garrard and McNaughton, is flawed; it 'includes some dreadful propensities' (54). This common condition, they hold, gives us reason to unconditionally forgive.

So far as it goes, I'm not against having sympathy with other people or recognizing that we, as humans, are liable to make mistakes. In this respect, I'm not against being forgiving. But I'm not sure that this means that we should forgive unconditionally, without regard for the perspective of the person being forgiven. As we've seen, we have reason to want more from other people than sympathy with our 'moral frailty' or concern for our welfare, growth, and development. We have reason to want people to take us seriously as moral peers, to allow our moral agency to bear on our relations with them. I thus doubt that unconditional forgiveness is generally justified

${ }^{21}$ For an account of these events, see Berman 2015.

22 It's worth emphasizing, again, that taking someone seriously as a moral peer doesn't require accepting their perspective or refraining from criticizing or blaming them. I also don't mean to claim that such wrongdoers have any standing to complain about not being taken seriously. Still, I think it is important to see that unconditional forgiveness involves forgoing a valuable way of relating to other people. Even in the cases I've adduced in this section, where I think this disvalue is eclipsed by other values, recognizing this is crucial for our overall picture. It also, as we'll see, plays a role in determining what good candidate reasons are for thinking the cases under discussion are cases of justified unconditional forgiveness. 
by its being a good way to be oriented toward other people. And I don't see why that would change in the foregoing cases. ${ }^{23}$

Still, there are other considerations that might sometimes vindicate unconditional forgiveness. For example, some psychological research suggests that unconditional forgiveness is of great therapeutic value. If this is right, then perhaps such forgiveness is sometimes justified as a healthy way of handling moral injury. ${ }^{24}$

Alternatively, it could be that unconditional forgiveness is sometimes justified by the way it can inspire moral change in the other person. This thought is connected to an idea that Angela Smith advances, regarding tolerance (Smith 2011, 191-4). Smith worries that attitudes of tolerance are impertinent or condescending. Still, in some cases, when people hold views that deny the equal membership of others in society, adopting an attitude of tolerance towards them, Smith argues, might serve as an important way to model appropriate behavior and inspire positive moral change. Smith quotes James Baldwin, who, writing to his nephew in 1962, advises:

There is no reason for you to try to become like white people and there is no basis whatever for their impertinent assumption that they must accept you. The really terrible thing, old buddy, is that you must accept them. And I mean that very seriously. You must accept them and accept them with love. For these innocent people have no other hope. They are, in effect, still trapped in a history which they do not understand; and until they understand it, they cannot be released from it. (Baldwin 1962, 8-9)

Just as Smith sees a lesson about tolerance in Baldwin's advice, there might also be a lesson about forgiveness. Unconditional forgiveness might be another way to try to develop in other people a more appropriate and thoughtful understanding of moral matters, one that can serve as the basis for a meaningful and healthy moral and political relationship. Of course, as Smith points out, this attitude is condescending. Engaging with someone in a way that aims at their moral development seems more fitting as a way to relate to children. Such condescension, though, might nevertheless be appropriate in cases in which other people's immoral

${ }^{23}$ One might wonder whether the people being forgiven in the foregoing cases really have an interest in being taken seriously as moral peers. I think they do, insofar as they're moral agents, although they may not have standing to complain about not being taken seriously.

24 This will depend, of course, on whether there are other healthy ways of handling moral injury, such as coming to terms with it or reframing how what happened fits into one's own life. 
perspective makes relating to them as a peer infeasible. It might sometimes be the best available option if one wants to instigate or develop a functional moral or political relationship with those people. ${ }^{25}$

Finally, I suspect that unconditional forgiveness can sometimes serve an important expressive function, which might vindicate it in certain contexts. Unconditional forgiveness, I believe, can allow one to stand for justice and to assert one's own personhood in the face of wrongdoings that threaten one's own moral status. ${ }^{26}$ Notably, this expressive function seems tied up with the way unconditional forgiveness doesn't take seriously the person being forgiven as a moral peer.

Let's return to the case of Dylann Roof. When Roof's victims forgave him, part of the expressive power of this gesture rested in the way it ignored Roof's perspective, rejecting it as having any bearing on their relations with him. From Roof's perspective, that is, his actions had a particular meaning and reflected the significance of certain deplorable values. By forgiving him unconditionally, his victims refused to even countenance this perspective. Their forgiveness, that is, presumed to settle the issue between them without any regard for Roof's view of things. And they thus asserted their own perspective, their rejection of his racism and hatred, as the only legitimate one. This, I think, is part of what makes the family members' forgiveness so powerful; it is a bold assertion of what's right.

For similar reasons, unconditional forgiveness in such contexts can serve another function: it can bolster one's own standing, allowing one to assert oneself as a self-respecting person in a distinctive way. Some wrongdoing, such as Roof's, doesn't merely contradict our values, but also serves to challenge our very personhood. In such cases, unconditional forgiveness can serve as an important rejoinder. And this isn't merely through asserting one's own view of oneself as a self-respecting person. It is also through delegitimizing the other person's view, positioning one's own normative perspective, one's view of oneself as a self-respecting person, as the only one

${ }^{25}$ One might wonder whether unconditional forgiveness, if it is used as a way to inspire moral change, as a way to instigate a healthier moral relationship, really represents a failure to take the other seriously as a moral peer. My sense is that it does. My valuing you as a potential moral peer is not yet to engage with you as a moral peer. Thanks to Barbara Herman and Betty Stoneman for helping me think about this.

${ }^{26}$ As I mentioned in the introduction, the arguments against unconditional forgiveness have typically been that it either risks condoning wrongdoing or fails to be self-respecting. If I'm right about this expressive function of unconditional forgiveness, we have reason to doubt that unconditional forgiveness must fail to take seriously wrongdoing in these ways. Although this isn't to say it cannot fail in them. 
that counts within the context of one's relations with the other person. This is a way of asserting one's own personhood as something that can't be called into question by other people.

In some cases, then, unconditional forgiveness offers the victim of injustice or the victim whose personhood has been challenged a distinctive way of asserting themselves and their moral perspective. It allows them to rise above, rather than merely stand against, what happened. It allows them to take control of the narrative, so to speak. And this, I believe, might sometimes vindicate unconditional forgiveness.

Where does all of this leave us? What does it mean for how we should think about the moral value of unconditional forgiveness? I think it means that it is simply complicated. Unconditional forgiveness, I believe, can sometimes serve important social and moral ends. However, it also involves abandoning a valuable way of relating to other people, and this is lamentable. When they're at their best, our social and moral lives are shared, reciprocal. There is thus something tragic about cases in which unconditional forgiveness becomes necessary. It means the forgiver has been left to navigate what happened on their own. In such cases, unconditional forgiveness may become important, even admirable, but not without remainder. ${ }^{27}$

\section{Works cited}

'Abortion Clinic Prayer' No Date. Retrieved from https://www.miamiarch.org/ Atimo_s/news/Abortion_Facility-Prayer_N_Guidelines.pdf.

Baldwin, James. 1962. The Fire Next Time. New York: Vintage International.

Beglin, David. 2020. 'Two Strawsonian Strategies for Accounting for Morally Responsible Agency.' Philosophical Studies 177: 2341-64.

Berman, Mark. 2015. “I Forgive You." Relatives of the Charleston Church Shooting Victims Address Dylann Roof.' The Washington Post. Retrieved from https://www.washingtonpost.com/news/post-nation/wp/2015/06/19/ i-forgive-you-relatives-of-charleston-church-victims-address-dylann-roof/.

Bennett, Christopher. 2018. 'The Alteration Thesis.' Philosophy and Public Affairs 46: 207-33.

27 Thanks to David Copp, John Martin Fischer, Barbara Herman, Agnieszka Jaworska, Coleen Macnamara, David Shoemaker, two anonymous referees, and audiences at the Eastern APA, Florida International University, UC Davis, and NOWAR for feedback on this paper. Finally, special thanks to Monique Wonderly both for feedback and for encouraging me to pursue the ideas here in the first place. 
Calhoun, Cheshire. 1992. 'Changing One's Heart'. Ethics 103: 76-96.

Fricker, Miranda. 2016. 'What's the Point of Blame? A Paradigm Based Explanation.' Noûs 50: 165-83.

Gamlund, Estlund. 2010. 'Supererogatory Forgiveness.' Inquiry 53: 540-64.

Garrard, Eve and McNaughton, David. 2003. 'In Defence of Unconditional Forgiveness.' The Proceedings of the Aristotelian Society 103: 39-60.

Garrard, Eve and McNaughton, David. 2011. 'Conditional Unconditional Forgiveness.' In C. Fricke, ed., The Ethics of Forgiveness. New York: Routledge, pp. 97-106.

Griswold, Charles. 2007. Forgiveness: A Philosophical Exploration. Cambridge: Cambridge University Press.

Hieronymi, Pamela. 2001. 'Articulating an Uncompromising Forgiveness.' Philosophy and Phenomenological Research 62: 529-55.

Holmgren, Margaret. 1993. 'Forgiveness and the Intrinsic Value of Persons.' American Philosophical Quarterly 30: 341-52.

Holmgren, Margaret. 2012. Forgiveness and Retribution: Responding to Wrongdoing. Cambridge: Cambridge University Press.

Kolnai, Aurel. 1973. 'Forgiveness.' Proceedings of the Aristotelian Society 74: 91-106.

McGeer, Victoria. 2012. 'Co-Reactive Attitudes and the Making of the Moral Community.' In C. MacKenzie and R. Langdon, eds., Emotions, Imagination, and Moral Reasoning. New York: Psychology Press, pp. 299-326.

McKenna, Michael. 2012. Conversation and Responsibility. Oxford: Oxford University Press.

Macnamara, Coleen. 2015. 'Reactive Attitudes as Communicative Entities.' Philosophy and Phenomenological Research 90: 546-69.

Murphy, Jeffrie. 1982. 'Forgiveness and Resentment.' Midwest Studies in Philosophy 7: 503-16.

Murphy, Jeffrie and Hampton, Jean. 1988. Forgiveness and Mercy. Cambridge: Cambridge University Press.

Novitz, David. 1998. 'Forgiveness and Self-Respect.' Philosophy and Phenomenological Research 58: 299-315.

Owens, David. 2012. Shaping the Normative Landscape. Oxford: Oxford University Press.

Pettigrove, Glen. 2004. 'Unapologetic Forgiveness.' American Philosophical Quarterly 41: 187-204.

Pettigrove, Glen. 2012. Forgiveness and Love. Oxford: Oxford University Press. 


\section{DAVID BEGLIN}

Shiffrin, Seana. 2000. 'Paternalism, Unconscionability Doctrine, and Accommodation.' Philosophy and Public Affairs 29: 205-50.

Shoemaker, David. 2007. 'Moral Address, Moral Responsibility, and the Boundaries of the Moral Community'. Ethics 188: 70-108.

Shoemaker, David. 2015. Responsibility from the Margins. Oxford: Oxford University Press.

Smith, Angela. 2011. 'The Trouble with Tolerance.' In R.J. Wallace, R. Kumar, and S. Freeman, eds., Reasons and Recognition: Essays on the Philosophy of T.M. Scanlon. Oxford: Oxford University Press, pp. 179-99.

Smith, Angela. 2013. 'Moral Blame and Moral Protest.' In D.J. Coates and N. Tognazzini, eds., Blame: Its Nature and Norms. Oxford: Oxford University Press, pp. 27-48.

Swinburne, Richard. 1989. Responsibility and Atonement. Oxford: Oxford University Press.

Talbert, Matthew. 2012. 'Moral Competence, Moral Blame, and Protest.' Journal of Ethics 16: 89-109.

Walker, Margaret Urban. 2006. Moral Repair: Reconstructing Moral Relations after Wrongdoing. Cambridge: Cambridge University Press.

Warmke, Brandon. 2016. 'The Normative Significance of Forgiveness.' Australasian Journal of Philosophy 94: 687-703.

Watson, Gary. 1987. 'Responsibility and the Limits of Evil: Variations on a Strawsonian Theme.' In F. Schoeman, ed., Responsibility, Character, and the Emotions: New Essays. Cambridge: Cambridge University Press, pp. 256-86.

Watson, Gary. 2013. 'Standing in Judgment.' In D.J. Coates and N. Tognazzini, eds., Blame: Its Nature and Norms. Oxford: Oxford University Press, pp. 282-302. 